\title{
Activation in resource networks: a comparative study of ports
}

Debbie Harrison

Håkan Håkansson

Norwegian School of Management BI

\begin{abstract}
In this paper we present two cases of ports. The first case is concerned with the creation of Skavsta airport in Sweden. Grenland Port in Norway is the focus of our second case. There are two research questions for this paper. The first has to do with what happens to existing resources when a new actor tries to activate them. The second question has to do with how single resources can be combined in new ways without creating changes in a network structure. In the latter sections of this paper we attempt to connect these two questions by comparing the two cases. The key finding of the paper is that resource development can occur without changing the structure of a network.
\end{abstract}

\section{INTRODUCTION}

Harbours have been important for thousands of years and there are many cities that have developed around suitable sites. They have, in many cases, been a resource that has created activities and prosperity. In the last 50 years, the same has been true for airports. Harbours and airports are important ingredients in the infrastructure in most countries and belong to the same resource category as roads, railways, power transmission grids and telecommunication networks.

For many years, a systems view based on a "natural monopoly assumption" has been dominating, which has lead to these resources being taken care of by governments. One consequence has been that these resources have been "administered" more than "managed". However, during the last decade we have seen a new trend emerge where such resources have become actors who are free to try to develop their own resources as well as to combine these with other chosen actors. This is the starting point for this paper. What can an actor do to increase the value of such a resource?

In order to study this issue, we have chosen to start from two cases - one harbour and one airport. Both cases regard ports, which have gone through an important change in terms of how they have been defined as an actor. The first case is concerned with the activation of Skavsta airport in Sweden - an airport that was constructed in the 1930's but modernised in the 1990's. Grenland Port in Norway, designed as an actor in the 
early 1990's through a merger of several smaller ports located close to each other, is the focus of our second case.

The cases will be used to investigate two general research issues. The first has to do with what a new actor can do regarding activating an existing set of resources. This issue can be formulated as how can a set of related resources be activated into a more powerful network through the activities of a new business unit? The new actor can combine in a new way both how a set of resources are related to each other and thereby how they can be related to important counterparts.

The second question has to do with how a new resource can become valued by an existing set of resources without changing the basic network structure. This issue can be formulated as how can a new resource be combined with existing ones in order to become valued without changing a network in a substantial way. In the latter sections of this paper, we attempt to connect these two questions via a comparison of the two case examples.

\section{RESOURCE NETWORKS}

In the resource-based view of the firm, resources with particular characteristics; e.g. uniqueness, underpin sustainable competitive advantage for a single organisation. The ability of an individual firm to compete is based upon the resources owned by that organisation. In this within-the-firm perspective, the value of a resource is centred in the properties of that resource (Barney 1991, 2001; Conner and Prahalad 1996), Eisenhardt and Schoonhoven 1996; Grant 1991; Priem and Butler 2001; Wernerfelt 1984, 1995).

In this paper we adopt a network perspective concerning resources. Our discussion is centred upon role and function of resources within business networks. Relationships across business actors facilitate access to, and the use of, both internal and external resources. Our focus is not on the properties of a given resource, but how value is created from combinations of resources within a business network.

The view of business networks that underpins this paper is the industrial network approach. "The industrial network is a specific structure which binds together actors, activities, and resources in a certain pattern" (Hakansson and Johanson (1988:375). In other words, three interrelated networks - actors, activities and resources - form the structure of the industrial network. In this paper, we focus upon the resource layer in the 
ARA model, or the resource network. An actor embedded in a network of relationships has access to the resources of other actors. Therefore actors control resources both directly and indirectly through exchange relationships. Resources are embedded in industrial activities.

What are some of the key dimensions of resources within the industrial network perspective? One fundamental assumption is that of resource heterogeneity. Resource use is dynamic and can be changed over time. In other words, resources are not fixed. Instead, bundles of resources can be configured in different ways (Penrose 1959; Alchian and Demsetz 1972).

"Resources are combined, developed, exchanged or created by use of other resources " (Hakansson 1987:15). Resources within and across organisations are combined, and it is in the combination of resources that value is located. The implication is that any one resource does not have value in itself. Instead, value comes from productive use when combined with other resources (Penrose 1959). A resource that is unconnected to others is 'blank'. Any one given resource does not have properties of uniqueness, etc. In sum, resources are dynamic because of the heterogeneity assumption and hence can always be used in other combinations, and in other business relationships, at least over time (Hakansson and Snehota 1995).

In our paper, we begin with resources per se, rather than actors accessing resources. We focus upon the interfaces between different types of resources, both social and physical, and actor-resource interfaces. What is gained by this focus? To study the interfaces between resources illustrates how they are used at a point in time and how the utilisation has developed through time. How does one resource mark another within a combination? To recognise that resources and actors have connections and how these can mark each other is also of interest. Actor bonds, activity links and resource ties concentrate upon ties within the respective network layer. To focus upon resource-actor linkages cuts across the familiar network layers of analysis.

The tools we are using for this paper is the recently developed framework by Waluszewski and Håkansson (2002). In this framework, resources are divided into two general types; physical and organisational. More specifically, physical resources can be sub-divided into products and facilities. Similarly, organisational resources can be split into two; business units and business relationships. The categorisation can be illustrated 
through the use of an example. A chemical company may develop a particular range of gases for industrial use; e.g. the product resource. These gases are manufactured within a production facility and this may incorporate many interconnected machines and industrial processes. A business unit owns the production facility, where the sales and purchasing functions may also take place. The business unit has a business relationship with another business unit, for example, that of a customer or a supplier.

The interfaces or connections that combine these four resource types can be within-type; e.g. business unit-business unit, or across type; e.g. business unit-facility. In other words, it is possible to study resource interaction, utilisation and development in a systematic way by investigating the connections between a focal resource and resources of the same type and to map the interfaces across resource types.

The more efficient use of a resource is concerned with doing the same thing better, through learning more about a resource and how it relates to counterpart resources. The use of an existing resource within an interface can be changed for developmental purposes. The dimensions of a resource can be altered, thereby changing the interface and the way in which the resources are used. New interfaces can be created across resources that were previously unconnected. Another possibility is to introduce a new resource, or multiple resources, into existing combinations, perhaps through accessing the resources of a new business partner. Here there are multiple possibilities for efficiency and development through creating new resource interfaces and hence joining previously unconnected resources.

A small number of studies have focused specifically upon the resource layer, in investigating resource development and resource utilisation; e.g. Håkansson and Waluszewski (2002), Wedin (2001) and Holmen (2001). Among many things, each of these studies illustrates the importance of increasing knowledge about the resource layer. This paper contributes to our understanding of networks by combining an active view of resources as being able to combine, rather than simply be combined in a passive way, and how this impacts upon network development.

Resource interfaces can be activated or mobilised within an existing dyad, a new dyad, and within a network. Studies have discussed the mechanisms by which customers can interface with their suppliers' resources within an existing relationship (Araujo et al 1999). A new actor is required to seek complementarities across internally controlled 
resources and those of potential partners. Previously unconnected resources would be activated in creating new resource interfaces. These interfaces need to be created in order for a new actor to establish a position with in an existing network. An actor with few resources may require the use of a large number of external resources.

The activation of resources at the network level can be considered in two broad ways. The issue of where the resource activation begins can be dealt with by assessing the network effects of changes within a dyad. Alternatively, there may be instances whereby an initiating resource node within a network activates an existing collection of resource interfaces. This node has a more network-level perception of the possibilities for activation in influencing the development of a network.

What are the consequences of the activation for a network as a whole? Lundgren (1992) separates mobilisation processes in networks into two categories. These can usefully be applied to the study of resource networks. The first category is "network integrative mobilisation, which refers to the process of expanding or extending the network in accordance with existing activity cycles". The second category of mobilisation is "network changing mobilisation, which refers to the process of establishing new activity cycles or the breaking of old ones or the combining of two or more previously unrelated activity cycles".

The activation of resources may be network integrative, in that new resources may be added to the structure of an existing network of resources. Further, resource activation may change the way in which a network operates. It might be that one central resource activates sets of resources within an existing resource network. This does not change the structure of the network per se, but instead has developmental implications as existing interfaces are changed in some way within the network. In the next section of the paper we present two cases. Both of the cases illustrate the activation of resources within existing networks.

\section{SKAVSTA AIRPORT: MOBILISING AND CONNECTING RESOURCES INTO AN EXISTING NETWORK}

Skavsta airport, situated $90 \mathrm{~km}$ south of Stockholm, was built in the 1930's by the military and was used by the Swedish air force until the 1970's. Ever since the military left the establishment, the local government has tried to attract air traffic to Skavsta. In 
the early 1990's, the airport still consisted of a piece of land, a runway, some standard landing equipment and a small, very simple terminal building. It was mainly used by local flying clubs; for sporadic helicopter landings; etc. The revenues from these activities were close to nothing. These were the circumstances when a small project group, in 1994, got the assignment to turn this more or less idle airfield into a commercial airport.

\section{Existing network around established airports}

What were the potential organisational resources to interface with? What groups of actors are dependent to some extent upon an airport? We can group these organizations into three categories. First, we have those organisations such as the airline companies that use an airport as a primary resource. These organizations are directly basing their business on the existence of one or several airports. Secondly, we have those organisations such as freight companies who use airports as one part of a resource system that also includes other complementary/competing resources (railways, harbours etc). The third group consists of all those who utilise the airport, mainly through the utilisation of the organisations in either of the first two groups, e.g. users of freight services or customers to airlines. Airports as actors, of course, belong to the first group.

There is a strong web of relationships among the established actors. For example, each airline has developed a certain traffic-structure that is based upon the use of particular airports. SAS uses Arlanda and Kastrup as the two main hubs. Among the travel organisers, some operate with one or two large central airports, while others co-operate with several regional ones. The Swedish Ving-Resor, for example, has actively developed a very decentralised structure with departures to tourist charter-destinations from 14 different airports in Sweden. Airports, as actors, are related to each other through the ways in which other actors combine them. Among airline companies, the most common way of combining airports is a "hub-and-spoke" structure, as this has been shown to give the best utilisation of planes and, crews and to keep the customers within their own activity structure.

An airport can be considered as a collection of tightly and loosely coupled facility resources that are represented by and/or owned by one or several business units. Certain facility resources, such as runways and landing equipment, are directly connected to the fundamental functions of an airport. This is the narrow facility 
constellation. The necessary resources that are central to the activity systems of an airport further interface with a wider facility resource constellation of which the directly connected resources are just a part. These are the facility resources of actors such as airlines and ground-handling companies that are tied to the airport in the resource network. Furthermore, there are all the other resources that are needed to relate the airport to the users in terms of transportation to and from the facility, terminals for cargo and all the resources needed for handling streams of planes, goods, people and luggage.

The activities performed at an airport have to be performed in an efficient way. Time is important as well as costs. However, even more important, is that the activities at the airport are synchronised and integrated with all connected activities. The total network of activities performed at, and in connection to, an airport is extensive and full of interdependencies. The efficiency of the activity pattern depends upon the actors and the functions involved. There could be benefits from co-ordinating certain types of activities, while such a solution only creates difficulties for others. One example of such an efficiency problem is the handling of air-cargo at many large international airports. Arlanda airport handles both international and domestic passenger traffic and airfreight (in the belly of passenger planes as well as in pure freighter aircrafts). When there is high traffic, the co-ordination of take-offs and landings of chartered freighter aircrafts has to be integrated into the scheduled traffic-pattern. If there is any delay the next slot time might be several hours later.

This is one of the reasons why some airports have brought together resources directed to a much more limited and/or specifically designed set of activities. For example, as a consequence of the rapid growth of airfreight transport, there has been the development of specialised freight airports. One example is Airborne who bought an airport and turned it into a freight hub.

\section{Finding a place in an existing network}

The starting-point for the Skavsta project group was a simple set of basic resources. In order for Skavsta to become something more than a simple airfield, it had to become part of the network described above, in terms of being related to a number of products, facilities, business units, and business relationships. 
One major problem for Skavsta was that it was not perceived to be an actor, but rather as a body of simple resources belonging to the local government. It was lacking relationships with other actors and, as a consequence, it was also lacking an identity. Some market research was conducted with airlines, shipping agents and industrial companies. Most agreed that Skavsta could be an interesting alternative - however always "for someone else". Every actor was already part of an existing network, with an established activity pattern and investments connected with existing airports. However, 1500-2000 companies with direct or indirect relationships with airports were now at least aware of the existence of Skavsta.

The project group then realised that they had to work with single counterparts. One group that could be approached was the companies belonging to the third group. In other words, industrial companies only indirectly linked to the established airports, such as the end customers of airport freight services. Such companies had no direct investments in the established ports, but often indirect investment through business relationship interfaces with the freight companies. "Our own message was rather simple", stated the project-leader at Skavsta: "We have an airfield but not much more than that - i.e. you can do whatever you find suitable”. In other words, the design of the resource interfaces, and the overlaying activity structures, could be started from new.

The group organised a meeting with ten of the largest producers in Sweden and they were lucky as the meeting came exactly at the right time for Ericsson. Ericsson had had some problems with road transport (security for valuable cargo) and the company was also in a period of large growth. One key problem faced by many industrial customers using Arlanda was the complexities of dealing with increasing volumes of freight cargo within the established activity pattern. Ericsson, in particular, faced some major problems. Ericsson became, in the middle of the 1990's, a very large user of airfreight services, accounting for approximately 50,000 tonnes or $25 \%$ of the total volume of aircargo handled in Sweden each year.

In 1997, Ericsson shipped 20 percent of their total volume of air-cargo from Skavsta. Most shipments were $70 \%$ Ericsson cargo, supplemented with goods from other industrial companies. The volumes were large enough to be economical from the start. Ericsson had knowledge resources regarding international airfreight but few physical 
resources. Together, the two actors designed the new freight airport to be closely adapted to Ericsson's requirements.

Once a set of resources and an activity structure for performing airfreight at Skavsta was established, there were a number of companies with smaller freight volumes that were interested in linking themselves to it. In other words, one crucial business relationship closely marked the new resource collection represented by the business unit.

The development of the airport resource constellation and activity pattern was also closely marked by a second important business relationship, with the airline KLM. This airline was the only one that showed some interest before Ericsson became a user. Furthermore, Skavsta also needed a partner to take care of the ground-handling activities at Skavsta. A ground-handling company, CSC (owned by KLM), became a new partner. By the late 1990's, KLM had daily freight departures from Skavsta. Thus the interaction with KLM and their ground-handling company CSC provided the airport with further specialised resources and competence within the freight area.

Now Skavsta had started to become an interesting actor. It was at this time that a third counterpart who could benefit from Skavsta's simple and loosely structured activity pattern joined the network. Ryan Air was a company searching for an airport within a 100-kilometre radius of Stockholm to establish a new low-cost route to London. With simple but functional solutions for necessary service activities, such as selling tax-free merchandise through "a hole in the wall", this co-operation turned out to be a great success. The number of passengers travelling through Skavsta increased from 20,000 in 1996 to 132,000 in 1997.

\section{Becoming valuable to a network from within}

In economic terms, a network effect is when one resource becomes more valuable by connecting other resources to it (as in a telephone network where the value of being part is directly related to the number of subscribers). The consequence of this is that it can then become a much more interesting actor for others. Five years after the project group formed, Skavsta was the third largest freight airport in Sweden (after Landvetter in Gothenburg and Arlanda). Approximately 200,000 passengers use Skavsta, although the economic base is mainly constituted by the relationships with Ericsson, Ryan Air and KLM. Skavsta had become valuable which is demonstrated by the fact that, in 1998, it was purchased by the British company TBI for more than 20 million Euro. 


\section{MOBILISING AND CONNECTING RESOURCES INTO A NETWORK THROUGH A NEW BUSINESS UNIT}

The concentration of industry in the Grenland Port area is the largest industrial cluster in Norway. The heavy industries include paper, metals, plastics, agriculture and cement. The companies in the umbrella include Borealis (plastics), Norcem (cement), Norsk Hydro (chemicals), Eramet (alloys), and Norske Skog (paper). There are several key shipping companies that are important for the Port including NorCargo (Norwegian coastal service) and DFDS Tor Line. Grenland Port is Norway's largest port for general cargo and one of the ten largest ports in the country. Ten million tonnes of goods were handled through the Port in 2001. An increasing volume of the tonnage is in containers, although at present, the majority of the goods are transported in bulk.

The geographical region that the Port Authority manages covers three navigable watercourses from Langesund Bay to Skien. There are 3,500 ship calls per year, including liners and ships on regular routes. There are facilities for handling both containers and cargo in LO/LO and RO/RO systems. There are 27 harbours that can be placed within the Port Authority umbrella. Of the 27, 4 belong to the Port Authority, and companies in the area privately own the others.

The ten national ports have priority from the Norwegian government for rail and road infrastructure. In terms of rail, the major problem is the weak connection to Drammen, Kristiansand and Oslo. This is because the route runs alongside the Farris Lake and because the dimensions of local rail tunnels impose velocity limitations for 30-40 kilometres.

\section{Developing a position and developing an existing network}

The Grenland Port Authority was created as a business unit in 1992 when the harbours in three local municipalities were combined to form one large port. The three ports of Postgrunn, Bamble and Skien used to operate as single business unit resources. Three municipalities, Postgrunn, Bamble and Skien, own one third of the Port Authority. With the new resource in place, users could interface with one large port administration covering the whole physical area rather than three separate business units.

The role of the Port Authority is to co-ordinate the network of previously passively connected resources from the three smaller ports. The resources are both publicly and privately owned. The Port Authority considers that it has a wide range of customers 
under the umbrella of "all the harbour users"; e.g. ship owners, harbour users, private industry, etc. A multitude of services are offered, such as; quays, loading and discharging, rental of forklift trucks, three large container cranes, etc. The Port Authority manages four public quays/general cargo terminals: Skien Havneterminal, Langesund, Herøya/Postgrunn and Brevik. The Grenland Port area ships directly to Sweden, Denmark, Germany, Finland and the UK.

The most important facility interfaces for the Authority are with the four public quays, i.e. Skien, Langesund, Herøya and Brevik. The Authority owns different mixes of resources at each quay. Further, there are differences in whether the Port Authority or other companies operates each quay. The most important interface is with the Brevik terminal. This is the largest terminal, but also the one that is international. Further, the set of resources at Brevik are combined both with the other three public quays, and with some of the private quays in the area also.

Skien Havneterminal at Vold is both owned and operated by the Port Authority. The largest user of the facility is Norske Skog (paper). Langesund quay is owned by the Port Authority and operated by Norcargo. Herøya is both owned and operated by Norsk Hydro, one of the major companies in the network. The Port Authority owns two quays at the Herøya site, the Deep-water quay and the Crane quay. Both Norsk Hydro and Eramet use the Deep-water quay.

Prior to 1992, the four quays were only passively connected. This was because they were located in the three once-separate ports. The main interfaces in place were with the various users of the quays. For example, large DFDS ships used to sail to Herøya to collect cargo from Norsk Hydro. This transportation pattern was inefficient because the size of the ships used meant that sailings were only once weekly. Subsequently, the Port Authority has activated resource interfaces across the four quays and significantly altered the patterns of utilisation.

One of the four quays, Brevik, has a certification to handle dangerous goods, the only harbour in the area that has this competence. In the late 1990's, there was a development plan to increase the amount of short sea cargo flows into Grenland. Brevik was developed as the international inter-modal hub. An objective of the Port Authority was to have frequent routes to many harbours in Europe. In 1999, a ro-ro terminal opened at Brevik, in addition to the existing lo-lo facilities. 
In becoming the international quay for Grenland, Brevik is the key facility node for the majority of shipments into and out of the Port. The three other public quays are strongly 'marked' by Brevik because most of the cargo is routed through Brevik. The Port Authority owns the harbour and the cranes, and Europaterminalen Brevik AS operates it, providing the trucks and stackers. New facilities have been purchased by the Port Authority and put in place; e.g. a large container crane.

The addition of new resources influences the possibilities for industry because different shipping lines are now able to operate at Grenland. New facilities meant that the site increased in value to DFDS Tor Line, the main counterpart for Brevik. DFDS ships cover the vast majority of the international routes and have added new routes. This further increased the value of Brevik to industrial users and their customers, and has altered transportation patterns into and out of the area. The creation of a feeder boat from Herøya to Brevik linking to DFDS services has increased the utilisation of Brevik and DFDS and added a new facility resource. DFDS operates relatively large ships that transport a large proportion of cargo goods from the area to various European destinations including Ghent, Rotterdam and Immingham.

The Port Authority forecasts that movements of unitised cargo will increase between 2002 and 2010 at a rate of $8-14 \%$ per annum. Alongside absorbing forecasted turnover increases there is a strategic issue regarding where to site a new rail connection to central Norway and Oslo. This is crucial for the expansion of the Port in the future for both imports and exports of goods. The central question then becomes which of the existing public quays are to be developed and when in terms of time and volume? How can the Port Authority co-ordinate the existing resources to further combine them, and what should be developed or newly combined for future expansion? The development of these facilities involves trade offs and conflicts amongst them.

The Port Authority has a strategic plan for the period 2002-2010 to develop the Brevik quay to absorb the forecasted increase in unitised cargo. Beyond 2010, there is a conflict of potential and investment between Herøya and Vold. Both are possibilities for expansion for the Port Authority, yet both cannot be activated to the same extent simultaneously. The location of a new rail link would substantially impact upon the utilisation and development of one of the quays. 


\section{CASE COMPARISON AND ANALYSIS}

Both of the cases presented above are examples of how resources are used and developed in a network setting. An interesting issue is to consider what is affecting the value in the use of certain resources and how this is related to single actors and their relationships, and therefore the resource network.

There were some very basic 'fundamental' resources in place prior to the development of Skavsta as a freight hub; e.g. an equipped airfield and a simple terminal building. The project group represented the initiating, or resource activating, actor. The project group managed both to link into existing resource combinations and to build a new resource combination.

The linking into existing resource combinations required finding potential partners because Skavsta airport had initially no relationships (and thus no identity). Hence, what was required was to break into the existing resource network, dominated by Arlanda, through finding resource interfaces that were weak in some way or to find complementary ties. The chosen counterparts had weak(er) interfaces to Arlanda that were characterised by indirect and 'light' ties. This was coupled with the high capacity utilisation of the existing resource constellation at Arlanda. The potential new resource interfaces - the interface with Ericsson - did not break established interfaces, but interfaces were developed in a certain way that was positive for Skavsta and its resources. They became valuable for someone! In all networks, there are possibilities to find changes where a new resource can be added and to create increased value for some of the involved actors who have earlier experienced problems.

Skavsta continued through a sequential creation of new resource interfaces with a limited number of partners to develop the value of its resources. In other words, through creation of new interfaces, the resources became better used. This further increased the value for those already using them. For Ericsson, one positive aspect was the lack of resources and the lack of an established activity pattern. The freight handling activity structure could, as a consequence, be developed jointly by Ericsson and Skavsta. Ericsson brought experience and knowledge resources, coupled with a demand resource. Skavsta almost became a part of Ericsson because of the 'perfect' match to Ericsson's internal resources. 
However, Skavsta was subsequently used by several customers, partly because of the use by Ericsson of the set of resource interfaces that were put in place. In other words, there was a set of resources created that was then attractive to others because there were possibilities to connect. Other actors could access the newly created constellation and add additional interfaces. For instance, CSC added specialised knowledge resources into the new airport and extended the set of interfaces in the process. The co-operation with Ryan Air is also an example of two parties having complementary resources. Ryan Air needed to utilise a low cost airport, and, at the same time, to attract large numbers of passengers to the airport.

Prior to the creation of the Grenland Port Authority there was a resource constellation of resource interfaces. Many of the resources were in place prior to the creation of the new business unit. The role of the Port Authority was to develop or activate the existing resource network in order to become a more interesting actor for existing and potential counterparts.

In order to become more attractive for external parties, the Grenland Port Authority had to first increase the utilisation of the Brevik terminal, partly by influencing existing relational interfaces between resources (facility and business unit). First, new facilities were created on-site; e.g. a RO-RO capability. In doing so, new interfaces could be created with shipping lines for new international locations. In parallel to the development of the Brevik terminal, the Port Authority strengthened the existing relationships across all four of the public terminals by increasing the specialisation. However, this can also lead to conflicts. The siting of the rail connections is such issue here.

The siting of the rail connection requires a strategic choice as it will have an extensive positive development for the facility that is chosen. There are conflicts amongst the public quays on this issue, because all the facility resources cannot be developed simultaneously, and hence developing one of the quays will preclude at least some development on the others. In other words, there are trade-offs and conflicts in resource co-ordination. If Vold were chosen as the site for the new rail link, this facility would grow faster than the others, influencing the interfaces amongst them.

Thus, in the Grenland Port case, the new business unit resource was an initiating node for resource network development. In developing a network position - a co-ordination 
role and key relationships - the Authority activated many resource combinations and shaped the network. The mobilisation function of the Authority changed activity patterns and resource connections.

\section{DISCUSSION}

Both cases indicate how single resources get their value in networks and how a resource network can increase in value. The key issue is to find combinations that are complementary to other combinations. In the Skavsta case, the project group succeeded to link into existing resource combinations without changing the established network in any larger way. In the same way, the new business unit Grenland Port managed to develop or activate single resources by finding new ways to relate them to each other and to some new external ones without changing the network structure.

Each of the new business unit resources represented the 'initiating actor' for resource activation within the two respective networks. These two activating nodes increased the utilisation of passively connected, often basic, resources and in doing so, raised the value of a resource to counterparts.

The change processes show some distinct features. The first one is that in both cases, there is a sequential creation of new resource interfaces with a limited number of partners. It seems that it is not possible to find a total solution in one step - it has to evolve gradually - and also that there must be just a few actors involved in each step. The second is that there must be a joint creation of activity structures or joint altering of the activity structures. It is when several actors change their activity structures in a synchronised way that the value of the resources can be increased in a substantial way. The third is that development can also take place through adding possibilities for others to connect - to find and connect potentially complementary resources and/or changing resources so they become complementary. The fourth and final feature is that even the absence of developed resources can be attractive as in the Skavsta case. The reason is that "less developed resources" might give the user larger possibilities to initiate joint development to suit the characteristics of their own resources.

The issue regarding the location of the new rail link in the Grenland case highlights the trade-offs and conflicts in resource co-ordination. Not all single resources or passive resource combinations can be activated to the same extent simultaneously. The 
development of a resource in co-ordination with a counterpart precludes the development of other resources, at least to some extent. The further value of a particular resource may be centred upon specialization or/and increased utilisation that changes the value of the resource network even if the attractiveness of other single resources is diminished.

In sum, this paper considered how resources are used and developed in a network setting and illustrates the importance of studying both resource-resource interfaces and resource-actor interfaces, and their role in shaping resource network value.

\section{REFERENCES}

Alchian, A. A. and Demsetz, H. (1972). Production, information costs and economic organisation, American Economic Review, Vol. 62: 777-795.

Araujo, A., Dubois, A., and Gadde, L-E. (1999). Managing Interfaces with Suppliers, Industrial Marketing Management, Vol. 28: 497-506.

Barney, J. B. (1991). Firm resources and sustained competitive advantage, Journal of Management, Vol. 17: 99-120.

Barney, J. B. (2001). Is the Resource-Based "View" a Useful Perspective for Strategic Management Research? Yes, Academy of Management Review, Vol. 26 (1): 41-56.

Conner, K. R. and Prahalad, C. K. (1996). A resource-based theory of the firm: Knowledge versus opportunism, Organizational Science, Vol. 7: 477-501.

Dierickx, I. and Cool, K. (1989). Asset stock accumulation and sustainability of competitive advantage, Management Science, Vol. 35: 1504-1511.

Easton, G. (1992). Industrial Networks: A Review, in B. Axelsson and G. Easton (1992), Industrial Networks: A New View of Reality, London: Routledge

Eisenhardt, K. M. and Schoonhoven, C. B. (1996). Resource-based view of strategic alliance formation: Strategic and social effects in entrepreneurial firms, Organization Science, Vol. 7: 136-150.

Grant, R. M. (1991). The resource-based theory of competitive advantage: Implications for strategy formation, California Management Review, Vol. 33 (3): 114-135.

Hakansson, H. (1987). Industrial Technological Development: A Network Approach, London: Croom Helm.

Hakansson, H. and Johanson, J. (1992). A model of Industrial Networks, in B. Axelsson and G. Easton, Industrial Networks: A New View of Reality, London: Routledge. 
Hakansson, H. and Snehota, I. (1995). Developing Relationships in Business Networks, London: Routledge.

Håkansson, H. and Waluszewski, A. (2002). Managing Technological Development IKEA, the environment and technology, London: Routledge.

Holmen, E. (2001). Notes on a Conceptualisation of Resource-Related Embeddedness of Interorganisational Product Development, $\mathrm{PhD}$ dissertation, Institute for Marketing, University of Southern Denmark.

Lundgren, A. (1992). Coordination and mobilisation processes in industrial networks, in B. Axelsson and G. Easton, Industrial Networks: A New View of Reality, London: Routledge.

Penrose, E. T. (1959). The Theory of the Growth of the Firm, New York: Oxford University Press.

Priem, R. L. and Butler, J. E. (2001). Tautology In The Resource-Based View And The Implications Of Externally Determined Resource Value: Further Comments, Academy of Management Review, Vol. 26 (1): 57-66.

Priem, R. L. and Butler, J. E. (2001). Is the Resource-Based "View" a Useful Perspective for Strategic Management Research?, Academy of Management Review, Vol. 26 (1): 22-40.

Wedin, T. (2001). Networks and Demand: The Use of Electricity in an Industrial Process, doctoral thesis number 82, Department of Business Studies, Uppsala University.

Wernerfelt, B. (1984). A resource-based view of the firm, Strategic Management Journal, Vol.5: 171-180.

Wernerfelt, B. (1995). A resource-based view of the firm: Ten years after, Strategic Management Journal, Vol.15: 171-174. 